\title{
Hyperoxia toxicity in septic shock patients according to the Sepsis-3 criteria: a post hoc analysis of the HYPER2S trial
}

Julien Demiselle ${ }^{1,2+}$, Martin Wepler ${ }^{3,4+}$, Clair Hartmann ${ }^{3,4 \dagger}$, Peter Radermacher ${ }^{3 *}$, Frédérique Schortgen ${ }^{5}$, Ferhat Meziani ${ }^{6,7}$, Mervyn Singer ${ }^{8}$, Valérie Seegers ${ }^{1}$ and Pierre Asfar ${ }^{1,2}$ (D) on behalf of the HYPER2S investigators

\begin{abstract}
Background: Criteria for the Sepsis-3 definition of septic shock include vasopressor treatment to maintain a mean arterial pressure $>65 \mathrm{mmHg}$ and a lactate concentration $>2 \mathrm{mmol} / \mathrm{L}$. The impact of hyperoxia in patients with septic shock using these criteria is unknown.

Methods: A post hoc analysis was performed of the HYPER2S trial assessing hyperoxia versus normoxia in septic patients requiring vasopressor therapy, in whom a plasma lactate value was available at study inclusion. Mortality was compared between patients fulfilling the Sepsis-3 septic shock criteria and patients requiring vasopressors for hypotension only (i.e., with lactate $\leq 2 \mathrm{mmol} / \mathrm{L}$ ).

Results: Of the 434 patients enrolled, 397 had available data for lactate at inclusion. 230 had lactate $>2 \mathrm{mmol} / \mathrm{L}$ and $167 \leq 2 \mathrm{mmol} / \mathrm{L}$. Among patients with lactate $>2 \mathrm{mmol} / \mathrm{L}, 108$ and 122 were "hyperoxia"- and "normoxia"-treated, respectively. Patients with lactate $>2 \mathrm{mmol} / \mathrm{L}$ had significantly less COPD more cirrhosis and required surgery more frequently. They also had higher illness severity (SOFA $10.6 \pm 2.8$ vs. $9.5 \pm 2.5, p=0.0001$ ), required more renal replacement therapy (RRT), and received vasopressor and mechanical ventilation for longer time. Mortality rate at day 28 was higher in the "hyperoxia"-treated patients with lactate $>2$ mmol/L as compared to "normoxia"-treated patients (57.4\% vs. $44.3 \%, p=0.054)$, despite similar RRT requirements as well as vasopressor and mechanical ventilation-free days. A multivariate analysis showed an independent association between hyperoxia and mortality at day 28 and 90 . In patients with lactate $\leq 2 \mathrm{mmol} / \mathrm{L}$, hyperoxia had no effect on mortality nor on other outcomes.
\end{abstract}

Conclusions: Our results suggest that hyperoxia may be associated with a higher mortality rate in patients with septic shock using the Sepsis-3 criteria, but not in patients with hypotension alone.

Keywords: Septic shock, Sepsis-3, Hyperoxia, Hyperlactatemia, Oxygen transport, Oxygen extraction

\footnotetext{
*Correspondence: peter.radermacher@uni-ulm.de

${ }^{\dagger}$ Julien Demiselle, Martin Wepler, Clair Hartmann have contributed equally to this work

${ }^{3}$ Institut für Anästhesiologische Pathophysiologie und

Verfahrensentwicklung, Universitätsklinikum, Helmholtzstrasse 8-1,

89081 Ulm, Germany

Full list of author information is available at the end of the article
}

\section{Springer Open}

C The Author(s) 2018. This article is distributed under the terms of the Creative Commons Attribution 4.0 International License (http://creativecommons.org/licenses/by/4.0/), which permits unrestricted use, distribution, and reproduction in any medium, provided you give appropriate credit to the original author(s) and the source, provide a link to the Creative Commons license, and indicate if changes were made. 


\section{Background}

According to the Third International Consensus Definitions (Sepsis-3), a diagnosis of septic shock requires a need for vasopressor treatment to maintain mean arterial pressure (MAP) $>65 \mathrm{mmHg}$ and a plasma lactate concentration $>2 \mathrm{mmol} / \mathrm{L}$ despite adequate volume resuscitation [1]. The latter takes into account the notion that circulatory shock "represents an imbalance between oxygen supply and oxygen requirements" typically associated with hyperlactatemia, which "reflects abnormal cellular function" [2]. Applying these more rigorous criteria for septic shock could affect the results of treatment comparisons in randomized controlled trials (RCT). Indeed, a recent post hoc analysis of the VASST trial comparing vasopressin and norepinephrine in septic shock [3] demonstrated that their sample size would have decreased by about half using the Sepsis-3 criteria with a higher overall mortality. Notably, day 28 mortality was significantly lower in vasopressin-treated patients with baseline lactate levels $\leq 2 \mathrm{mmol} / \mathrm{L}$, whereas no difference was seen in those patients with lactate $>2 \mathrm{mmol} / \mathrm{L}$ [4].

Our recently published multicenter RCT of "Hyperoxia and Hypertonic Saline in Patients with Septic Shock (HYPER2S)" compared mechanical ventilation either with an inspiratory oxygen concentration of $100 \%\left(\mathrm{~F}_{\mathrm{i}} \mathrm{O}_{2}\right.$ 1.0; "hyperoxia") during the first $24 \mathrm{~h}$ and $\mathrm{F}_{\mathrm{i}} \mathrm{O}_{2}$ set to target an arterial hemoglobin oxygen saturation of 88-95\% ("normoxia") [5]. All patients enrolled had septic shock as characterized by the need of vasopressor support (norepinephrine or epinephrine $\geq 0.1 \mu \mathrm{g} / \mathrm{kg} / \mathrm{min}$ ) despite $20 \mathrm{~mL} / \mathrm{kg}$ of crystalloid fluid resuscitation, but without threshold values for lactatemia at inclusion. The trial was stopped prematurely for safety reasons, with a higher mortality at day 28 in the "hyperoxia" group.

Hyperoxia administration in critically ill patients remains controversial. On the one hand, hyperoxia administration was thought to be crucial to compensate the imbalance between oxygen supply and demand [2, 6], and might be interesting in improving host defense against microbes (increase in phagocytosis and killing rate [7]) by the effect of the increased formation of reactive oxygen species [8-10]. On the other hand, there is growing evidence that hyperoxia may be toxic in such situation. The physiological effects of hyperoxia are multiple and are detailed in previous reviews [8, 11, 12]. A U-shaped relationship exists between oxygen arterial pressure during the first $24 \mathrm{~h}$ and mortality in ICU [13, 14]. More recently, studies have suggested that a restrictive administration of oxygen could be associated with lower mortality in ICU $[15,16]$.

Therefore, we hypothesized that in patients with septic shock and tissue hypoxia due to dysoxia, mirrored by increased arterial lactate, the effects of high oxygen concentration might be detrimental and related to increase the formation of reactive oxygen species.

Using the database of the HYPER2S-trial, we aimed at comparing the effects of hyperoxia on mortality and organ failures in patients with septic shock according to the Sepsis-3 criteria (lactate levels $>2 \mathrm{mmol} / \mathrm{L}$ ).

\section{Methods}

For all participating centers, the study design of the HYPER2S trial was approved by the ethics committee of the Angers University Hospital. Written informed consent was obtained from all patients, their next of kin, or another surrogate decision maker, as appropriate. If patients were unable to provide informed consent and the next of kin or a designated person was not available, the inclusion procedure for emergency situations was applied. Post hoc consent was obtained in these latter patients. The HYPER2S trial was registered with Clinicaltrial.gov (NCT 01722422).

\section{Patient Cohort HYPER2S}

We performed a retrospective analysis of data prospectively recorded during the HYPER2S trial. This RCT compared, in a two-by-two factorial design, mechanical ventilation with "hyperoxia" $\left(\mathrm{F}_{\mathrm{i}} \mathrm{O}_{2} 1.0\right)$ versus "normoxia" $\left(\mathrm{F}_{\mathrm{i}} \mathrm{O}_{2}\right.$ set to target an arterial hemoglobin oxygen saturation of $88-95 \%$ ) during the first $24 \mathrm{~h}$ of septic shock, and hypertonic saline versus isotonic saline for fluid resuscitation during the first $72 \mathrm{~h}$ of septic shock [5]. Septic shock had been identified by the need for vasopressor support (norepinephrine or epinephrine $\geq 0.1 \mu \mathrm{g} / \mathrm{kg} / \mathrm{min}$ ) despite $20 \mathrm{~mL} / \mathrm{kg}$ of crystalloid fluid resuscitation. The trial was stopped prematurely for safety reasons after enrolment of 442 patients ( 434 analyzable), as both mortality at day 28 $(p=0.12)$ and mortality at day $90(p=0.16)$ were higher in the hyperoxia-treated patients.

For the present post hoc analysis, we compared mortality rates in the 397 patients in whom lactate levels were available at baseline, representing $91.5 \%$ of the total study population. These patients were then subdivided into a Sepsis-3 shock subset (lactate $>2 \mathrm{mmol} / \mathrm{L}$, $n=230$ [53.0\%]) or those with vasopressor-dependent hypotension only (lactate $\leq 2 \mathrm{mmol} / \mathrm{L}, n=167$ [38.5\%]) [1] (Fig. 1). There was no significant difference in the distribution of the treatment arms between the two lactate groups ( $p=0.110, \chi^{2}$ test) (Fig. 1$)$.

\section{Statistical analysis}

In this post hoc analysis, only patients with available lactates at inclusion were included. Quantitative data were expressed as mean, standard deviation, median and interquartile range (IQR) for parametric and nonparametric distributions, respectively, and were compared using 


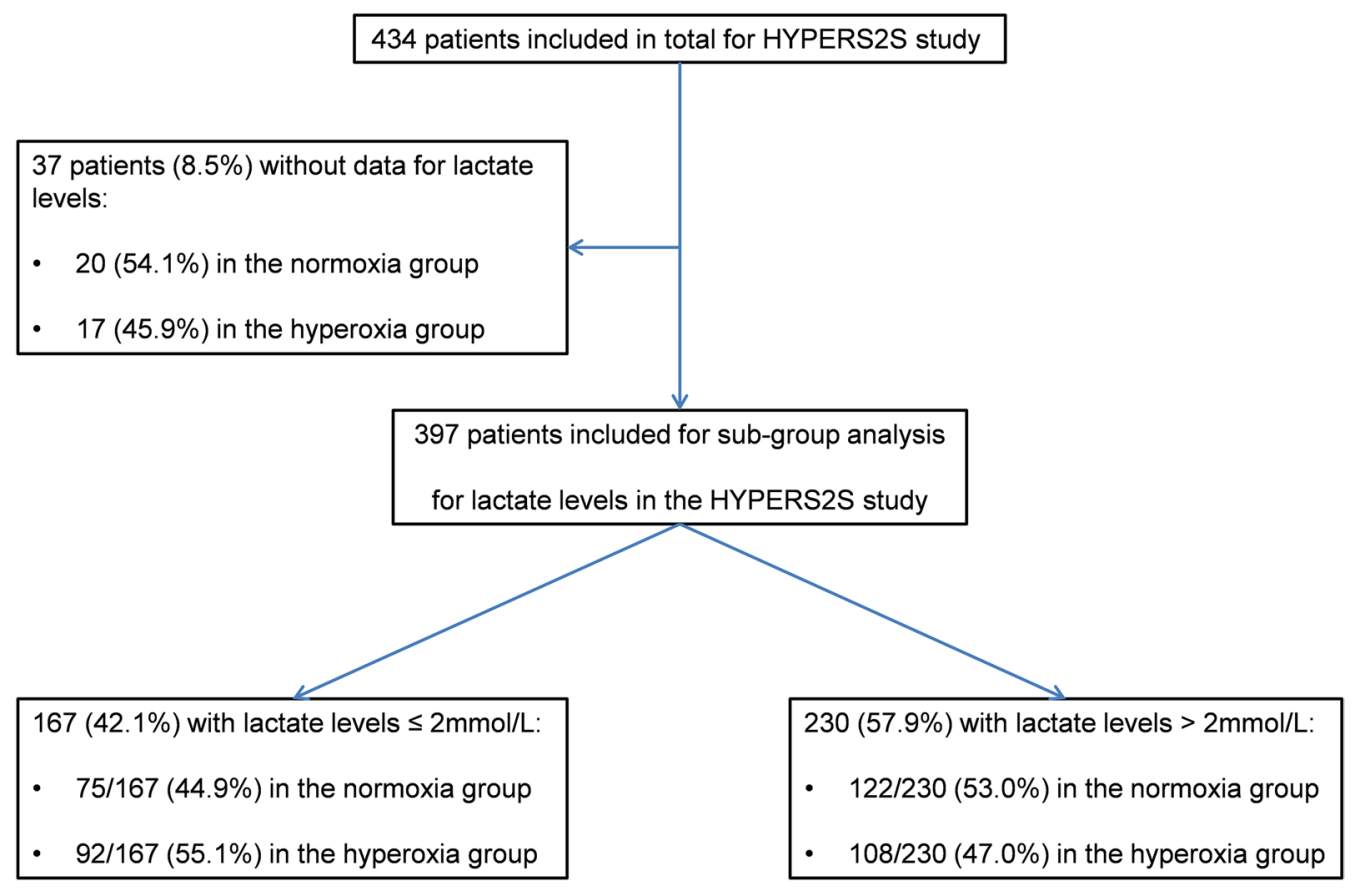

Fig. 1 Study population

Student's t tests or Wilcoxon rank-sum tests as appropriate. Qualitative variables were compared using $X^{2}$ or Fisher's exact test. Time-to-death was illustrated with Kaplan-Meier survival curves and group comparisons were performed using the log-rank test.

To identify factors associated with survival differences from inclusion to day 28 (primary endpoint) and from inclusion to day 90 as hazard ratios (HRs), Cox regression models were computed in landmark analyses. The assumption of proportional hazards was tested by analyzing Schoenfeld residuals. In the first step, univariate analyses were conducted for every inclusion characteristics variable (including randomization arm) independently of each other. In the second step, multivariate Cox regression models were built using variables with $p$ value $<0.2$ in univariate analysis. When some covariates were strongly correlated (i.e., lactate and arterial $\mathrm{pH}$ ), the most associated with survival was kept in the multivariate model. Since there was missing data for SAPS III (SAPS III was secondarily collected in the HYPER2S trial), SAPS II was chosen for the multivariate analyses. However, SAPS II and SAPS III values were well correlated (data not shown).

\section{Results}

Patients with lactate $>2 \mathrm{mmol} / \mathrm{L}$ were more likely to have cirrhosis, but less likely to have coronary artery disease and COPD (Additional file 1: Table S1). They were also more likely to have undergone surgery, in particular emergency surgery reflecting a much higher contribution of abdominal sepsis as the source of septic shock. They were more hypotensive, albeit nonsignificant, tachycardic, more acidotic and required higher norepinephrine infusion rates (Additional file 1: Table S1). Creatinine levels and the $\mathrm{PaO}_{2} / \mathrm{F}_{\mathrm{i}} \mathrm{O}_{2}$ ratio were higher (Additional file 1: Table S1). However, the number of patients with ARDS (as defined by a $\mathrm{PaO}_{2} / \mathrm{F}_{\mathrm{i}} \mathrm{O}_{2}<200 \mathrm{mmmHg}$ ) and bilirubin were similar in patients with lactate $>2$ or $\leq 2 \mathrm{mmol} / \mathrm{L}$. Accordingly, at inclusion, both SAPS II and SOFA scores were significantly higher in patients with baseline lactate $>2 \mathrm{mmol} / \mathrm{L}$ (Additional file 1: Table S1).

Throughout their ICU stay, patients with baseline lactate $>2 \mathrm{mmol} / \mathrm{L}$ needed renal replacement therapy (RRT) twice as frequently as patients with lactate $\leq 2 \mathrm{mmol} / \mathrm{L}$ and had fewer days free of vasopressor support and mechanical ventilation (Additional file 2: Table S2). Accordingly, daily SOFA scores were higher on days 1, 2, 3 , and 5 (Additional file 2: Table S2). Patients with baseline lactate $>2 \mathrm{mmol} / \mathrm{L}$ had a higher mortality at day 28 (50.4\% vs. $24.0 \% ; p<0.0001)$ and day $90(55.2 \%$ vs. $30.5 \%$; $p<0.0001)$ compared to patients with lactate $\leq 2 \mathrm{mmol} / \mathrm{L}$ (Additional file 3: Figure S1).

Except for sex ratio, no significant differences in baseline variables were seen between "hyperoxia" and "normoxia" groups for patients with lactate $>2 \mathrm{mmol} / \mathrm{L}$ (Table 1). Results were similar in patients with 
Table 1 Baseline characteristics of patients according to lactate level ( $\leq 2$ or $>\mathbf{2} \mathrm{mmol} / \mathrm{L}$ )

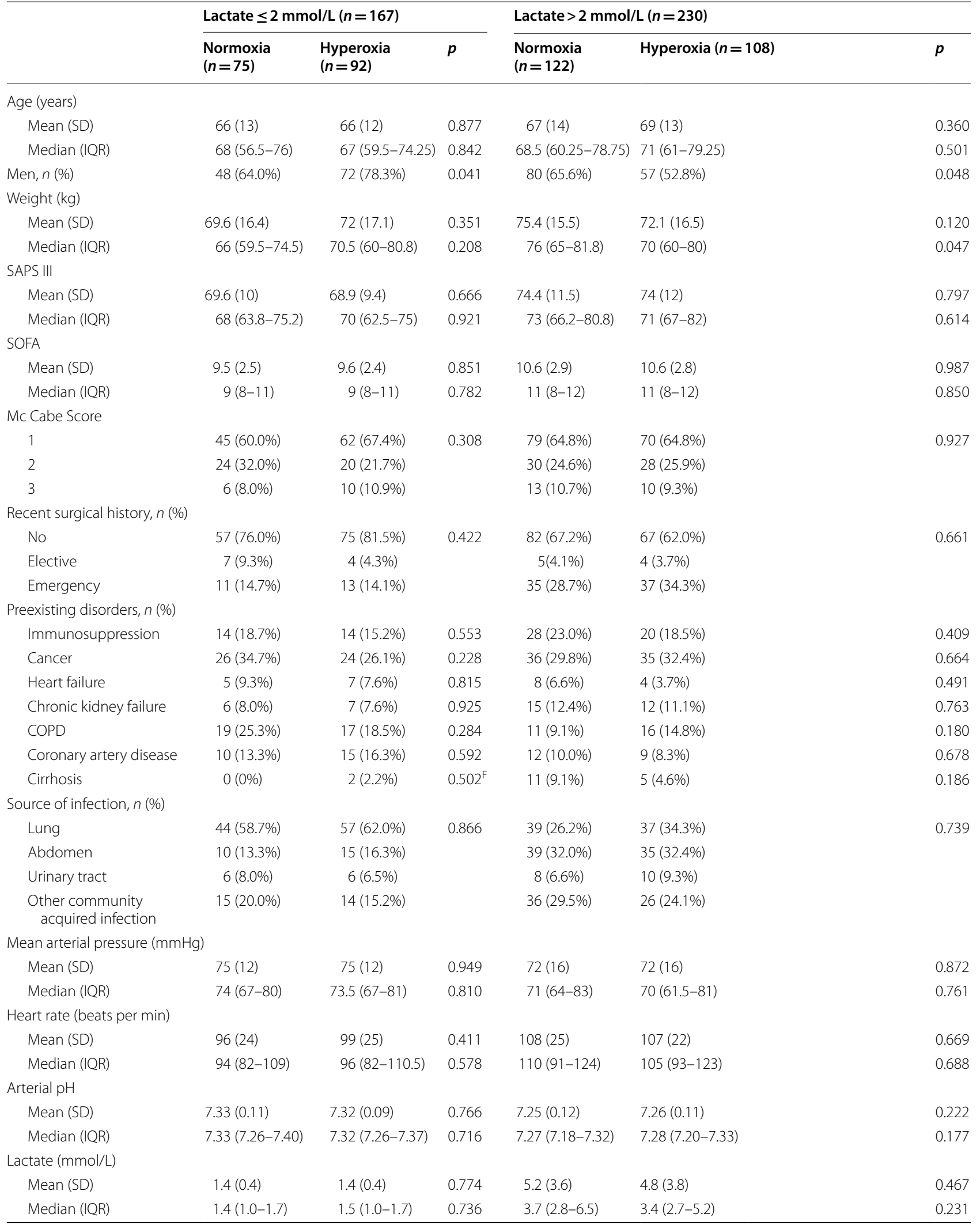


Table 1 (continued)

\begin{tabular}{|c|c|c|c|c|c|c|}
\hline & \multicolumn{3}{|c|}{ Lactate $\leq 2 \mathrm{mmol} / \mathrm{L}(n=167)$} & \multicolumn{3}{|c|}{ Lactate $>2 \mathrm{mmol} / \mathrm{L}(n=230)$} \\
\hline & $\begin{array}{l}\text { Normoxia } \\
(n=75)\end{array}$ & $\begin{array}{l}\text { Hyperoxia } \\
(n=92)\end{array}$ & $p$ & $\begin{array}{l}\text { Normoxia } \\
(n=122)\end{array}$ & Hyperoxia $(n=108)$ & $p$ \\
\hline \multicolumn{7}{|c|}{ Crystalloid fluid treatment before inclusion (mL) } \\
\hline Mean (SD) & $2883(1397)$ & $2631(1298)$ & 0.234 & $2876(1392)$ & $3003(1522)$ & 0.511 \\
\hline Median (IQR) & $2500(2000-3500)$ & $2250(2000-3000)$ & 0.147 & $2500(2000-3500)$ & $2500(2000-3625)$ & 0.684 \\
\hline \multicolumn{7}{|l|}{ Serum sodium (mmol/L) } \\
\hline Mean (SD) & $138(5)$ & $138(3)$ & 0.652 & $139(6)$ & $139(4)$ & 0.611 \\
\hline Median (IQR) & $138(134-142)$ & $139(136-141)$ & 0.431 & $139(136-142)$ & $139(136-142)$ & 0.545 \\
\hline \multicolumn{7}{|l|}{ Serum chloride (mmol/L) } \\
\hline Mean (SD) & $107(6)$ & $106(6)$ & 0.471 & $106(7)$ & $106(6)$ & 0.645 \\
\hline Median (IQR) & $106(103-111)$ & $105.5(103-109)$ & 0.448 & $105(102-109)$ & $105(102-111)$ & 0.355 \\
\hline \multicolumn{7}{|c|}{ Dose of norepinephrine ( $\mu \mathrm{g} / \mathrm{kg} / \mathrm{min})$} \\
\hline Mean (SD) & $0.44(0.38)$ & $0.56(0.65)$ & 0.137 & $0.79(0.82)$ & $0.75(0.74)$ & 0.701 \\
\hline Median (IQR) & $0.31(0.2-0.5)$ & $0.35(0.2-0.65)$ & 0.367 & $0.55(0.27-1.04)$ & $0.50(0.30-0.88)$ & 0.930 \\
\hline \multicolumn{7}{|l|}{$\mathrm{PaO}_{2} / \mathrm{F}_{i} \mathrm{O}_{2}$ ratio $(\mathrm{mmHg})$} \\
\hline Mean (SD) & $227(102)$ & $191(73)$ & 0.012 & $231(108)$ & $232(110)$ & 0.934 \\
\hline Median (IQR) & $207(143-265)$ & $175(131-235)$ & 0.023 & $198(143-301)$ & $202(149-293)$ & 0.876 \\
\hline $\begin{array}{l}\text { Patients with } \\
\mathrm{PaO}_{2}>120 \mathrm{mmHg}, n \text { (\%) }\end{array}$ & $37(49.3 \%)$ & $37(40.2 \%)$ & 0.238 & $72(59.0 \%)$ & $61(56.5 \%)$ & 0.698 \\
\hline $\begin{array}{l}\text { ARDS with } \mathrm{PaO}_{2} / \mathrm{F}_{\mathrm{i}} \mathrm{O}_{2} \\
\text { ratio }<200 \mathrm{mmHg}, n(\%)\end{array}$ & $36(48.0 \%)$ & $56(64.1 \%)$ & 0.096 & $61(50.0 \%)$ & $52(48.1 \%)$ & 0.779 \\
\hline
\end{tabular}

The Chi-square or Fisher test was used for qualitative data. The quantitative data were compared by t test for the mean comparison, Mann-Whitney test for median comparisons. $p$ values are reported without correction of the a risk despite multiple comparisons, $p$ values are presented for the comparison between "normoxia" and "hyperoxia" treatment in the lactate $\leq 2 \mathrm{mmol} / \mathrm{L}$ and lactate $>2 \mathrm{mmol} / \mathrm{L}$ groups, respectively. F Fisher, IQR interquartile range, COPD chronic obstructive pulmonary disease, SAPS simplified acute physiological score, SOFA sequential organ failure assessment

lactate $\leq 2 \mathrm{mmol} / \mathrm{L}$ except for a lower $\mathrm{P}_{\mathrm{a}} \mathrm{O}_{2} / \mathrm{F}_{\mathrm{i}} \mathrm{O}_{2}$ ratio in the "hyperoxia" group (Table 1).

Despite a lower SOFA score at days 5 and 7 in the patients with lactate $>2 \mathrm{mmol} / \mathrm{L}$ treated with hyperoxia, mortality at day 28 tended to be higher in these patients ( $44.3 \%$ vs. $57.4 \%, p=0.054$ ) (Fig. 2a). There was no difference between groups for RRT requirements, nor for the number of RRT, vasopressor support and mechanical ventilation-free days.

In patients with baseline lactate $\leq 2 \mathrm{mmol} / \mathrm{L}$, hyperoxia had no impact on mortality (Fig. 2b), need for RRT nor days free of RRT or vasopressor support (Table 2). However, hyperoxia was associated with fewer days free of mechanical ventilation and higher SOFA scores at days 2 and 3 (Table 2). SOFA components are detailed daily in the Additional file 4: Table S3.

During the ICU stay, infectious events occurred in 69 (17.6\%) patients (108 proven infectious events). There were more infectious events in the lactate $\leq 2 \mathrm{mmol} / \mathrm{L}$ group when compared to lactate $>2 \mathrm{mmol} / \mathrm{L}$ group ( $24 \%$ versus $12.6 \%, p=0.003)$, without difference in the delay between randomization and infectious event. Nosocomial infection's characteristics are presented in Additional file 5: Table S4.
The multivariate analysis showed that patients with lactate $>2 \mathrm{mmol} / \mathrm{L}$ treated with hyperoxia had higher risk of mortality at day 28 and 90 (HR 1.79 [1.21-2.63], $p<0.003$, and HR 1.57 [1.09-2.28], $p=0.016$, respectively) (Table 3 ). Upon the reviewing request, arguing a decrease in lactate clearance in patients with cirrhosis and septic shock, we have done the same analysis excluding cirrhotic patients. This analysis showed also a higher mortality at day 28 and 90 in patients with lactate $>2 \mathrm{mmol} / \mathrm{L}$ treated with hyperoxia (HR 1.95 [1.292.95], $p<0.002$, and HR 1.69 [1.15-2.50], $p=0.006$, respectively) (See Additional file 6: Table S5).

\section{Discussion}

This post hoc analysis of the HYPER2S trial aimed to assess the impact of the new Sepsis-3 septic shock criteria (vasopressor-dependent hypotension and hyperlactatemia despite adequate fluid resuscitation [1]) on the number of patients enrolled in the study and their mortality rate, and the effect of hyperoxemia. The Sepsis-3 criteria were fulfilled in $58 \%$ of the total study population, with mortality at day 28 being more than double that of the patients with vasopressor-dependent hypotension without a raised lactate level. Hyperoxia was associated with a higher mortality rate in patients fulfilling 
a

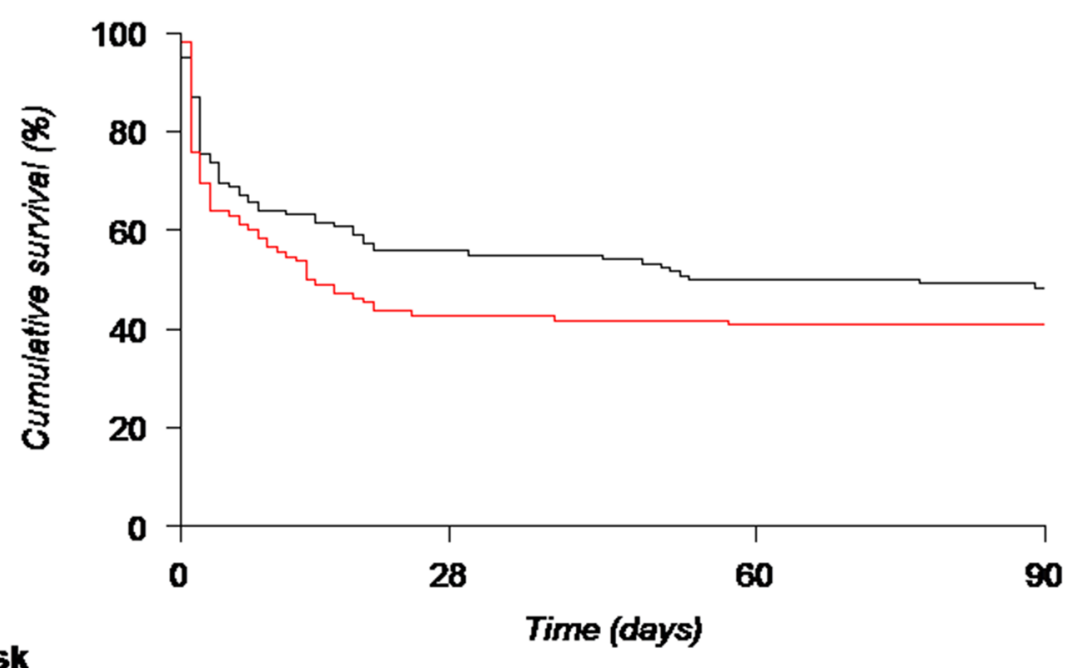

Number at risk

Time (days)

$\begin{array}{rrrrr}\text { Normoxia } & 122 & 68 & 61 & 59 \\ - \text { Hyperoxia } & 108 & 46 & 44 & 44\end{array}$

b



Number at risk

Fig. 2 Kaplan-Meier survival curve of the "hyperoxia" (red line) and "normoxia" (black line) groups for: a the subgroup of patients with hyperlactatemia $>2 \mathrm{mmol} / \mathrm{L}$ at baseline. Log-rank test between the two randomization arms, $p=0.054$ and $p=0.171$ at day 28 and 90 , respectively. b The subgroup of patients with lactatemia $\leq 2 \mathrm{mmol} / \mathrm{L}$ at baseline. Log-rank test between the two randomization arms, $p=0.680$ and $p=0.513$ at day 28 and 90, respectively

the Sepsis-3 shock criteria, while this association was not observed in patients with vasopressor-dependent hypotension alone (Additional file 6: Table S5).

The Sepsis-3 shock criteria were derived using the Surviving Sepsis Campaign database of 18.840 unselected septic patients with organ dysfunction [17]. Patients requiring vasopressors to maintain MAP $>65 \mathrm{mmHg}$ and with persisting hyperlactatemia $>2 \mathrm{mmol} / \mathrm{L}$ despite adjudged adequate fluid resuscitation had a $42.3 \%$ hospital mortality compared 
Table 2 Evolution of the clinical characteristics and illness severity scores of patients according to lactate level $(\leq 2$ or $>2 \mathrm{mmol} / \mathrm{L}$ ) and normoxia or hyperoxia treatment

\begin{tabular}{|c|c|c|c|c|c|c|}
\hline & \multicolumn{3}{|c|}{ Lactate $\leq 2 \mathrm{mmol} / \mathrm{L}(n=167)$} & \multicolumn{3}{|c|}{ Lactate $>2 \mathrm{mmol} / \mathrm{L}(n=230)$} \\
\hline & Normoxia $(n=75)$ & Hyperoxia $(n=92)$ & $p$ value & Normoxia $(n=122)$ & Hyperoxia ( $n=T 108$ ) & $p$ value \\
\hline Mortality at $d 28$ & $17(22.7 \%)$ & $23(25.0 \%)$ & $0.680^{¥}$ & $54(44.3 \%)$ & $62(57.4 \%)$ & $0.054^{¥}$ \\
\hline Mortality at $d 90^{¥}$ & $21(28.0 \%)$ & $30(32.6 \%)$ & $0.513^{¥}$ & $63(51.6 \%)$ & $64(59.3 \%)$ & $0.171^{¥}$ \\
\hline RRT & $14(18.9 \%)$ & $25(27.8 \%)$ & 0.185 & $50(42.7 \%)$ & $44(41.5 \%)$ & 0.853 \\
\hline Days without vasopressor, mean (SD) & $21(10)$ & $19(9)$ & 0.323 & $14(12)$ & $12(12)$ & 0.149 \\
\hline $\begin{array}{l}\text { Days without mechanical ventilation, } \\
\text { mean (SD) }\end{array}$ & $16(9)$ & $13(10)$ & 0.04 & $11(11)$ & $9(11)$ & 0.131 \\
\hline Days without RRT, mean (SD) & $24(9)$ & $22(10)$ & 0.12 & $16(12)$ & $13(12)$ & 0.139 \\
\hline $\begin{array}{l}\text { Survival at day } 28 \text { without organ } \\
\text { support, } n(\%)\end{array}$ & $54(73.0 \%)$ & $61(67.8 \%)$ & 0.47 & $58(49.6 \%)$ & $41(38.7 \%)$ & 0.102 \\
\hline \multicolumn{7}{|l|}{ SOFA ho } \\
\hline Mean (SD) & $9.5(2.5)$ & $9.6(2.4)$ & 0.851 & $10.6(2.9)$ & $10.6(2.8)$ & 0.987 \\
\hline Median (IQR) & $9(8-11)$ & $9(8-11)$ & 0.782 & $11(8-12)$ & $11(8-12)$ & 0.85 \\
\hline$n$ & 75 & 92 & & 122 & 108 & \\
\hline \multicolumn{7}{|l|}{ SOFA h24 } \\
\hline Mean (SD) & $9.4(2.6)$ & $9.8(3)$ & 0.273 & $11.9(3.3)$ & $11.6(3.4)$ & 0.526 \\
\hline Median (IQR) & $9(7-11)$ & $9(8-12)$ & 0.335 & $11(10-14)$ & $12(9-14)$ & 0.693 \\
\hline$n$ & 75 & 89 & & 112 & 104 & \\
\hline \multicolumn{7}{|l|}{ SOFA h48 } \\
\hline Mean (SD) & $7.8(3.3)$ & $9.6(3.6)$ & 0.001 & $10.8(4.1)$ & $10.8(3.6)$ & 0.962 \\
\hline Median (IQR) & $7(6-10)$ & $9(7-12)$ & 0.002 & $10(8-14)$ & $10(9-14)$ & 0.99 \\
\hline$n$ & 71 & 82 & & 93 & 80 & \\
\hline \multicolumn{7}{|l|}{ SOFA h72 } \\
\hline Mean (SD) & $6.6(3.9)$ & $8.4(4.4)$ & 0.008 & $9.9(4.6)$ & $9.2(4.4)$ & 0.374 \\
\hline Median (IQR) & $6(4-9)$ & $8(5-11)$ & 0.014 & $10(6.8-13)$ & $9(6-13)$ & 0.43 \\
\hline$n$ & 65 & 82 & & 88 & 71 & \\
\hline \multicolumn{7}{|l|}{ SOFA d4 } \\
\hline Mean (SD) & $6.3(4.2)$ & $6.9(4.4)$ & 0.436 & $8(4.7)$ & $6.9(3.8)$ & 0.136 \\
\hline Median (IQR) & $5(3-8)$ & $6(4-10)$ & 0.396 & $7(4-11)$ & $7(4-9)$ & 0.29 \\
\hline$n$ & 53 & 67 & & 69 & 57 & \\
\hline \multicolumn{7}{|l|}{ SOFA d5 } \\
\hline Mean (SD) & $5.9(3.9)$ & $6.1(3.9)$ & 0.815 & $8.3(4.8)$ & $6.4(3.9)$ & 0.024 \\
\hline Median (IQR) & $5.5(3-8)$ & $5(3-8)$ & 0.819 & $7(5-11)$ & $6(4-9)$ & 0.044 \\
\hline$n$ & 44 & 63 & & 62 & 51 & \\
\hline \multicolumn{7}{|l|}{ SOFA d 6} \\
\hline Mean (SD) & $5.5(3.8)$ & $5.8(3.9)$ & 0.704 & $7.8(4.8)$ & $6.4(4)$ & 0.108 \\
\hline Median (IQR) & $6(3-7)$ & $4(3-9)$ & 0.695 & $7(4.5-10)$ & $5.5(3-9)$ & 0.155 \\
\hline$n$ & 37 & 55 & & 59 & 44 & \\
\hline \multicolumn{7}{|l|}{ SOFA d7 } \\
\hline Mean (SD) & $5.4(3.6)$ & $5.8(4.2)$ & 0.726 & $8.1(5)$ & $4.9(3.4)$ & 0.001 \\
\hline Median (IQR) & $5(3-7)$ & $5(3-8)$ & 1 & $7(4-10.2)$ & $4(2-7)$ & 0.002 \\
\hline$n$ & 29 & 47 & & 48 & 34 & \\
\hline \multicolumn{7}{|l|}{$\mathrm{PaO}_{2} \mathrm{hO}$} \\
\hline Mean (SD) & $148.4(95.1)$ & $126.4(63.8)$ & 0.09 & 170 (105) & $151.1(82.9)$ & 0.139 \\
\hline Median (IQR) & 116 (92-172) & $113(85-144)$ & 0.289 & 139 (90-202) & $130(93-184)$ & 0.295 \\
\hline$n$ & 75 & 92 & & 122 & 108 & \\
\hline \multicolumn{7}{|l|}{$\mathrm{PaO}_{2} \mathrm{~h} 12$} \\
\hline Mean (SD) & $97.1(29.4)$ & 265.4 (119) & $<0.0001$ & $105.8(44.9)$ & $274.6(136)$ & $<0.0001$ \\
\hline Median (IQR) & $89(75-117)$ & $273(172-367)$ & $<0.0001$ & $96(70-124)$ & $277(158-364)$ & $<0.0001$ \\
\hline
\end{tabular}


Table 2 (continued)

\begin{tabular}{|c|c|c|c|c|c|c|}
\hline & \multicolumn{3}{|c|}{ Lactate $\leq 2 \mathrm{mmol} / \mathrm{L}(n=167)$} & \multicolumn{3}{|c|}{ Lactate $>2 \mathrm{mmol} / \mathrm{L}(n=230)$} \\
\hline & Normoxia $(n=75)$ & Hyperoxia $(n=92)$ & $p$ value & Normoxia $(n=122)$ & Hyperoxia $(n=T 108)$ & $p$ value \\
\hline$n$ & 69 & 86 & & 109 & 103 & \\
\hline \multicolumn{7}{|l|}{$\mathrm{PaO}_{2} \mathrm{~h} 24$} \\
\hline Mean (SD) & $89.3(27.7)$ & $221.3(115.8)$ & $<0.0001$ & $101.0(46.2)$ & $229.8(131.8)$ & $<0.0001$ \\
\hline Median (IQR) & $82(73-98.5)$ & $211(133-295)$ & $<0.0001$ & $91(77-109.2)$ & $210.5(119.8-322.8)$ & $<0.0001$ \\
\hline$n$ & 67 & 83 & & 100 & 92 & \\
\hline \multicolumn{7}{|l|}{$\mathrm{PaO}_{2} \mathrm{~h} 72$} \\
\hline Mean (SD) & $88.9(24.7)$ & $96.5(54.6)$ & 0.306 & $88.6(25.2)$ & $92.4(29.4)$ & 0.431 \\
\hline Median (IQR) & $84(71-101)$ & $82(74-107)$ & 0.801 & $84.5(71.8-96.8)$ & $86(74-98)$ & 0.481 \\
\hline$n$ & 55 & 69 & & 72 & 61 & \\
\hline
\end{tabular}

For mortality at day 28 and 90, respectively, an analysis in landmark with a log-rank test was used. For survival at day 28 without organ support and/or renal replacement therapy (RRT) a $\chi^{2}$ test was used. For the number of days without vasopressor therapy, without mechanical ventilation, and without RRT, respectively, a Student's $t$ test was used. $¥=$ log-rank test; for mortality at day 28 in patients with a lactate $>2 \mathrm{mmol} / \mathrm{L}: \chi^{2}$ test; $d$ day, $h$ hour

Table 3 Data analysis by using a Cox regression model with survival data censored at 28 days and then censored at 90 days in succession

\begin{tabular}{|c|c|c|c|c|c|c|c|c|}
\hline & \multicolumn{4}{|c|}{ Inclusion d28 } & \multicolumn{4}{|c|}{ Inclusion d90 } \\
\hline & HR & $95 \% \mathrm{Cl}$ & & $p$ value & HR & $95 \% \mathrm{Cl}$ & & $p$ value \\
\hline \multicolumn{9}{|c|}{ Univariate Cox model (universal analysis) } \\
\hline Sex (F vs M) & 1.59 & 1.12 & 2.24 & 0.013 & 1.51 & 1.06 & 2.14 & 0.021 \\
\hline Weight (per $10 \mathrm{~kg}$ increase) & 1 & 0.89 & 1.13 & 0.999 & 1.04 & 0.93 & 1.16 & 0.503 \\
\hline $\mathrm{pH}$ (per 0.1 increase) & 0.97 & 0.95 & 0.98 & $<0.001$ & 0.97 & 0.95 & 0.98 & $<0.001$ \\
\hline Hyperoxia vs normoxia & 1.44 & 1.00 & 2.07 & 0.051 & 1.28 & 0.91 & 1.82 & 0.160 \\
\hline SAPS 2 & 1.05 & 1.03 & 1.06 & $<0.001$ & 1.05 & 1.04 & 1.06 & $<0.001$ \\
\hline Mac Cabe & 1.25 & 0.97 & 1.62 & 0.089 & 1.25 & 0.98 & 1.61 & 0.073 \\
\hline $\mathrm{PaO}_{2} / \mathrm{FiO}_{2}$ & 1 & 0.99 & 1.00 & 0.860 & 1 & 0.99 & 1.00 & 0.660 \\
\hline Autoimmune disease & 1.17 & 0.76 & 1.80 & 0.480 & 1.262 & 0.84 & 1.89 & 0.260 \\
\hline \multicolumn{9}{|l|}{ Multivariate Cox model } \\
\hline Sex (F vs M) & 1.55 & 1.06 & 2.27 & 0.022 & 1.53 & 1.06 & 2.22 & 0.024 \\
\hline pH (per 0.1 increase) & 0.96 & 0.95 & 0.98 & $<0.001$ & 0.97 & 0.95 & 0.98 & $<0.001$ \\
\hline Hyperoxia vs normoxia & 1.79 & 1.21 & 2.63 & 0.003 & 1.57 & 1.09 & 2.28 & 0.016 \\
\hline SAPS 2 & 1.05 & 1.04 & 1.06 & $<0.001$ & 1.05 & 1.04 & 1.06 & $<0.001$ \\
\hline Mac Cabe & 1.07 & 0.82 & 1.39 & 0.613 & 1.06 & 0.83 & 1.37 & 0.640 \\
\hline
\end{tabular}

$H R$ hazard ratio, $C l$ confidence interval, $F$ female, $M$ male

to $30.1 \%$ with vasopressor-dependent hypotension alone. Comparable data were seen on retrospective analysis of the VASST study database [4] and the HYPER2S study. These higher mortality rates in the Sepsis-3 shock subset were reflected by the higher illness severity scores at baseline, and the requirement for more organ support therapy.

The retrospective analysis of the VASST study [4] revealed a significant outcome benefit from vasopressin only in those patients with vasopressor-dependent hypotension alone. Mortality was identical in patients fulfilling the Sepsis-3 shock criteria.
In this present analysis, we confirm that treatment effect may vary according to the criteria used for defining septic shock. Indeed, hyperoxia had no effect on mortality albeit a longer requirement for mechanical ventilation in vasopressor-dependent hypotensive patients, whereas there was a near-significant increase in mortality $(57.4 \%$ vs. $44.3 \%$ normoxia; $p=0.054$ ) in the Sepsis-3 shock cohort. Hyperlactatemia despite adequate fluid resuscitation is considered to reflect more severe cellular and metabolic abnormalities, and thus places affected patients at higher mortality risk [17].

There is a growing evidence that hyperoxia may be associated with higher mortality and that conservative 
strategies may contribute to lower mortality $[16,17]$. However, there is no certainty on the implicated pathophysiological mechanisms in oxygen toxicity. Indeed, the disparity in outcomes with hyperoxia only seen in those fulfilling the Sepsis-3 shock criteria suggests an additional toxic impact of oxygen in this more severe subset. Oxygen administration has long been considered a cornerstone in the management of patients with septic shock [9]. Circulatory shock is considered to "represent an imbalance between oxygen supply and oxygen requirements" [2]. While hyperoxia increases tissue oxygen tension, even in shock states with profound reduction of tissue oxygen transport [18], it can compromise macro- and microcirculatory blood flow $[8,11,19]$. After fluid resuscitation, septic shock generally has a "distributive shock" pattern, where the "main deficit lies in the periphery, ... with altered oxygen extraction" [2]. In most cell types, other than erythrocytes, oxygen is crucial for sufficient adenosine triphosphate synthesis via the mitochondrial oxidative phosphorylation, acting as the final electron acceptor in the respiratory chain. Oxygen is also one of the strongest oxidizing agents capable of damaging any biological molecule due to excess production of reactive oxygen species (ROS) [20]. Although ROS can also be generated with hypoxia, ROS formation is directly related to the level of arterial and tissue oxygen tension [21]. It is tempting to speculate that under conditions of profound alterations of cellular oxygen extraction and utilization-perhaps manifest clinically as hyperlactatemia-hyperoxia, with an increase in available oxygen, may lead to excessive ROS formation with subsequent oxidative stress-induced damage. In septic shock, ROS production and damage may be amplified by impaired mitochondrial respiration and depleted antioxidant defenses [22]. Even if this study has several limitations, discussed thereafter, it could be hypothesized that hyperoxia toxicity, with an increased oxidative stress due to ROS formation, may be delayed. This mid- or long-term harmful effect of hyperoxia may explain that most variates are not significantly different between oxygenation groups, except for some major patient-centered outcome variables. Hyperlactatemia may be due to excessive peripheral production or decrease clearance such as in cirrhosis. It was suggested by a reviewer to test our hypothesis without cirrhotic patients, and these additional results support our hypothesis.

Some limitations must be underlined in this analysis. First, the HYPER2S trial was stopped prematurely for safety reason. From a strict statistical point of view, mortality difference with hyperoxia in the Sepsis-3 shock cohort was not significant $(p=0.054)$. However, this is no longer true when results are adjusted on confounders (multivariate analysis). This is likely related to lack of power, as the absolute and relative mortality at day
28 rates increased by $13.1 \%$ and $29.6 \%$, respectively, in a sizeable number of patients (264). This suggests a clinical relevance of our results. Second, the post hoc character of the analysis, in a retrospective setting, may have missed some masked imbalance between groups and the frailty of multivariate analysis as well as multiple testing should be taken in account. Therefore, it is wise to consider these results as hypothesis generating, as the study has not the statistical power to conclude on a link between hyperoxia and mortality.

\section{Conclusions}

Results of this post hoc analysis of the HYPER2S trial suggest that hyperoxia treatment for $24 \mathrm{~h}$ in patients with septic shock fulfilling the Sepsis-3 definition may be associated with a higher mortality rate. Toxic effects of oxygen were not found in patients with sepsis and without hyperlactatemia, requiring vasopressors. Our results suggest a differential effect of oxygen according to the underlying cellular and metabolic status of the patient and may vary according to SEPSIS 2 or 3 definition. Due to post hoc design of our study, our results should be considered as hypothesis generating.

\section{Additional files}

Additional file 1: Table S1. Baseline characteristics of patients with lactate levels $>$ and $\leq 2 \mathrm{mmol} / \mathrm{L}$, respectively. For gender, recent surgical history, preexisting disorders, source of infection, and the number of patients with ARDS and with $\mathrm{PaO}_{2}>120 \mathrm{mmHg}$ at baseline $a x^{2}$ test was used. For the other parameters, a Student's $t$ test and Mann-Whitney rank sum test was used.

Additional file 2: Table S2. Clinical characteristics and illness severity scores of patients with lactate levels $>$ and $\leq 2 \mathrm{mmol} / \mathrm{L}$, respectively. For mortality at day 28 and 90, respectively, an analysis in landmark with a log-rank test was used. For survival at day 28 without any organ support and renal replacement therapy (RRT) a $x^{2}$ test was used. For the number of days without vasopressor therapy, without mechanical ventilation, and without RRT, respectively, and for the SOFA scores, a Student's $t$ test and a Mann-Whitney rank sum test was used. SOFA sequential organ failure assessment.

Additional file 3: Figure S1. Kaplan-Meier curves of all patients with hyperlactatemia (lactate $>2 \mathrm{mmol} / \mathrm{L})(n=230)$ and those with lactates $\leq 2 \mathrm{mmol} / \mathrm{L}$ at baseline $(n=167)$.

Additional file 4: Table S3. Daily evolution of the SOFA score's components of patients according to lactate level ( $\leq 2$ or $>2 \mathrm{mmol} / \mathrm{L})$ and normoxia or hyperoxia treatment.

Additional file 5: Table S4. Infectious events during the ICU stay of patients according to lactate level ( $\leq 2$ or $>2 \mathrm{mmol} / \mathrm{L}$ ) and normoxia or hyperoxia treatment.

Additional file 6: Table S5. Data analysis by using a Cox regression model with survival data censored at 28 days and then censored at 90 days in succession, excluding cirrhotic patients. HR hazard ratio, Cl confidence interval, $F$ female, $M$ male. 


\section{Authors' contributions}

JD, MW and $\mathrm{CH}$ interpreted data and drafted the manuscript. PR, FS and PA conducted the study, interpreted data and supervised manuscript drafting. FM and MS revised the manuscript VS did the statistical analysis. All authors read and approved the final manuscript.

\begin{abstract}
Author details
${ }^{1}$ Médecine Intensive et Réanimation, Médecine Hyperbare, Centre Hospitalier Universitaire, 4, Rue Larrey, 49933 Angers Cedex 9, France. ${ }^{2}$ LUNAM Université, Université d'Angers, Angers, France. ${ }^{3}$ Institut für Anästhesiologische Pathophysiologie und Verfahrensentwicklung, Universitätsklinikum, Helmholtzstrasse 8-1, 89081 Ulm, Germany. ${ }^{4}$ Klinik für Anästhesiologie, Abteilung Klinische Anästhesiologie, Universitätsklinikum, Albert-Einstein-Allee 23, 89081 Ulm, Germany. ${ }^{5}$ Service de Réanimation Adulte, Centre Hospitalier Intercommunal de Créteil, 40, Avenue de Verdun, 94010 Créteil Cedex, France. ${ }^{6}$ Faculté de Médecine, Hôpitaux Universitaires de Strasbourg, Service de Réanimation, Nouvel Hôpital Civil, Université de Strasbourg (UNISTRA), Strasbourg, France. ${ }^{7}$ INSERM (French National Institute of Health and Medical Research), UMR 1260, Regenerative Nanomedicine (RNM), FMTS, Strasbourg, France. ${ }^{8}$ Bloomsbury Institute of Intensive Care Medicine, University College London, London, UK
\end{abstract}

\section{Acknowledgements}

This article was supported by the Deutsche Forschungsgemeinschaft (Collaborative Research Center 1149) (PR), the GEROK program of the Deutsche Forschungsgemeinschaft and the Universitätsklinikum UIm (MW), and the Hertha-Nathorff-Fellowship of the Medical Faculty of Ulm University (CH).

\section{Competing interests}

The authors declare that they have no competing interests.

\section{Availability of data and materials}

The datasets used and/or analyzed during the current study are available from the corresponding author on reasonable request.

\section{Consent for publication}

Not applicable.

\section{Ethics approval and consent to participate}

The HYPER2S trial was approved by the ethics committee of the Angers University Hospital. Written informed consent was obtained from all patients, their next of kin, or another surrogate decision maker, as appropriate. If patients were unable to provide informed consent and the next of kin or a designated person was not available, the inclusion procedure for emergency situations was applied. Post hoc consent was obtained in these latter patients.

\section{Funding}

The HYPER2S trial was supported by the French Ministry of health. The funder of the study had no role in study design, data collection, data analysis, data interpretation, or writing of this report.

\section{Publisher's Note}

Springer Nature remains neutral with regard to jurisdictional claims in published maps and institutional affiliations.

Received: 20 June 2018 Accepted: 3 September 2018

Published online: 17 September 2018

\section{References}

1. Singer $M$, Deutschman CS, Seymour CW, et al. The third international consensus definitions for sepsis and septic shock (Sepsis-3). JAMA. 2016;315:801-10. https://doi.org/10.1001/jama.2016.0287.

2. Vincent J-L, De Backer D. Circulatory shock. N Engl J Med. 2013;369:1726-34. https://doi.org/10.1056/NEJMra1208943.
3. Russell JA, Walley KR, Singer J, et al. Vasopressin versus norepinephrine infusion in patients with septic shock. N Engl J Med. 2008;358:877-87. https://doi.org/10.1056/NEJMoa067373.

4. Russell JA, Lee T, Singer J, et al. The septic shock 3.0 definition and trials: a vasopressin and septic shock trial experience. Crit Care Med. 2017;45:940-8. https://doi.org/10.1097/CCM.0000000000002323.

5. Asfar P, Schortgen F, Boisramé-Helms J, et al. Hyperoxia and hypertonic saline in patients with septic shock (HYPERS2S): a two-by-two factorial, multicentre, randomised, clinical trial. Lancet Respir Med. 2017:5:18090. https://doi.org/10.1016/S2213-2600(17)30046-2.

6. Weil MH, Shubin H. The "VIP" approach to the bedside management of shock. JAMA. 1969;207:337-40.

7. Kotani N, Hashimoto H, Sessler Dl, et al. Supplemental intraoperative oxygen augments antimicrobial and proinflammatory responses of alveolar macrophages. Anesthesiology. 2000;93:15-25.

8. Hafner S, Beloncle F, Koch A, et al. Hyperoxia in intensive care, emergency, and peri-operative medicine: Dr. Jekyll or Mr. Hyde? A 2015 update. Ann Intensive Care. 2015. https://doi.org/10.1186/s1361 3-015-0084-6.

9. Knighton DR, Halliday B, Hunt TK. Oxygen as an antibiotic. The effect of inspired oxygen on infection. Arch Surg. 1984;119:199-204.

10. Waisman D, Brod V, Rahat MA, et al. Dose-related effects of hyperoxia on the lung inflammatory response in septic rats. Shock Augusta Ga. 2012;37:95-102. https://doi.org/10.1097/SHK.0b013e3182356fc3.

11. Asfar $P$, Singer $M$, Radermacher $P$. Understanding the benefits and harms of oxygen therapy. Intensive Care Med. 2015;41:1118-21. https ://doi.org/10.1007/s00134-015-3670-z.

12. Helmerhorst HJF, Schultz MJ, van der Voort PHJ, et al. Bench-to-bedside review: the effects of hyperoxia during critical illness. Crit Care Lond Engl. 2015;19:284. https://doi.org/10.1186/s13054-015-0996-4.

13. de Jonge E, Peelen L, Keijzers PJ, et al. Association between administered oxygen, arterial partial oxygen pressure and mortality in mechanically ventilated intensive care unit patients. Crit Care Lond Engl. 2008;12:R156. https://doi.org/10.1186/cc7150.

14. Helmerhorst HJF, Arts DL, Schultz MJ, et al. Metrics of arterial hyperoxia and associated outcomes in critical care. Crit Care Med. 2017;45:18795. https://doi.org/10.1097/CCM.0000000000002084.

15. Girardis M, Busani S, Damiani E, et al. Effect of conservative vs conventional oxygen therapy on mortality among patients in an intensive care unit: the oxygen-icu randomized clinical trial. JAMA. 2016:316:1583. https://doi.org/10.1001/jama.2016.11993.

16. Chu DK, Kim LH-Y, Young PJ, et al. Mortality and morbidity in acutely ill adults treated with liberal versus conservative oxygen therapy (IOTA): a systematic review and meta-analysis. The Lancet. 2018;391:1693-705. https://doi.org/10.1016/S0140-6736(18)30479-3.

17. Shankar-Hari M, Phillips GS, Levy ML, et al. Developing a new definition and assessing new clinical criteria for septic shock: for the third international consensus definitions for sepsis and septic shock (Sepsis-3). JAMA. 2016:315:775. https://doi.org/10.1001/jama.2016.0289.

18. Dyson A, Simon F, Seifritz A, et al. Bladder tissue oxygen tension monitoring in pigs subjected to a range of cardiorespiratory and pharmacological challenges. Intensive Care Med. 2012;38:1868-76. https://doi. org/10.1007/s00134-012-2712-z.

19. Donati A, Damiani E, Zuccari S, et al. Effects of short-term hyperoxia on erythropoietin levels and microcirculation in critically III patients: a prospective observational pilot study. BMC Anesthesiol. 2017. https:// doi.org/10.1186/s12871-017-0342-2.

20. Leverve XM. To cope with oxygen: a long and still tumultuous story for life. Crit Care Med. 2008;36:637-8. https://doi.org/10.1097/CCM.0B013 E31816296AD.

21. Jamieson $D$, Chance $B$, Cadenas $E$, Boveris $A$. The relation of free radical production to hyperoxia. Annu Rev Physiol. 1986;48:703-19. https://doi. org/10.1146/annurev.ph.48.030186.003415.

22. Brealey D, Brand M, Hargreaves I, et al. Association between mitochondrial dysfunction and severity and outcome of septic shock. Lancet Lond Engl. 2002;360:219-23. https://doi.org/10.1016/S0140-6736(02)09459-X. 